\title{
Quantitative trait loci and differential gene expression analyses reveal the genetic basis for negatively associated $\beta$-carotene and starch content in hexaploid sweetpotato [Ipomoea batatas (L.) Lam.]
}

\author{
Dorcus C. Gemenet ${ }^{1}(1)$. Guilherme da Silva Pereira ${ }^{2} \cdot$ Bert De Boeck $^{3} \cdot$ Joshua C. Wood $^{4} \cdot$ Marcelo Mollinari $^{2}$. \\ Bode A. Olukolu ${ }^{2,11} \cdot$ Federico Diaz $^{3} \cdot$ Veronica Mosquera $^{3} \cdot$ Reuben T. Ssali $^{5} \cdot$ Maria David $^{3} \cdot$ Mercy N. Kitavi $^{1}$. \\ Gabriela Burgos $^{3}$. Thomas Zum Felde ${ }^{3} \cdot$ Marc Ghislain $^{1} \cdot$ Edward Carey $^{6}$. Jolien Swanckaert ${ }^{6} \cdot$ Lachlan J. M. Coin $^{7}$. \\ Zhangjun Fei ${ }^{8}$. John P. Hamilton ${ }^{4} \cdot$ Benard Yada $^{9}$ - G. Craig Yencho ${ }^{2} \cdot$ Zhao-Bang Zeng $^{2} \cdot$ Robert O. M. Mwanga ${ }^{5}$. \\ Awais Khan ${ }^{3,10} \cdot$ Wolfgang J. Gruneberg ${ }^{3} \cdot$ C. Robin Buell ${ }^{4}$
}

Received: 12 July 2019 / Accepted: 17 September 2019 / Published online: 8 October 2019

(c) The Author(s) 2019

\begin{abstract}
Key message $\beta$-Carotene content in sweetpotato is associated with the Orange and phytoene synthase genes; due to physical linkage of phytoene synthase with sucrose synthase, $\beta$-carotene and starch content are negatively correlated. Abstract In populations depending on sweetpotato for food security, starch is an important source of calories, while $\beta$-carotene is an important source of provitamin A. The negative association between the two traits contributes to the low nutritional quality of sweetpotato consumed, especially in sub-Saharan Africa. Using a biparental mapping population of 315 $\mathrm{F}_{1}$ progeny generated from a cross between an orange-fleshed and a non-orange-fleshed sweetpotato variety, we identified two major quantitative trait loci (QTL) on linkage group (LG) three (LG3) and twelve (LG12) affecting starch, $\beta$-carotene, and their correlated traits, dry matter and flesh color. Analysis of parental haplotypes indicated that these two regions acted pleiotropically to reduce starch content and increase $\beta$-carotene in genotypes carrying the orange-fleshed parental haplotype at the LG3 locus. Phytoene synthase and sucrose synthase, the rate-limiting and linked genes located within the QTL on LG3 involved in the carotenoid and starch biosynthesis, respectively, were differentially expressed in Beauregard versus Tanzania storage roots. The Orange gene, the molecular switch for chromoplast biogenesis, located within the QTL on LG12 while not differentially expressed was expressed in developing roots of the parental genotypes. We conclude that these two QTL regions act together in a cis and trans manner to inhibit starch biosynthesis in amyloplasts and enhance chromoplast biogenesis, carotenoid biosynthesis, and accumulation in orange-fleshed sweetpotato. Understanding the genetic basis of this negative association between starch and $\beta$-carotene will inform future sweetpotato breeding strategies targeting sweetpotato for food and nutritional security.
\end{abstract}

Communicated by Jeffrey Endelman.

Dorcus C. Gemenet and Guilherme da Silva Pereira have contributed equally to this work.

Electronic supplementary material The online version of this article (https://doi.org/10.1007/s00122-019-03437-7) contains supplementary material, which is available to authorized users.

Dorcus C. Gemenet

d.gemenet@cgiar.org

Extended author information available on the last page of the article

\section{Introduction}

Sweetpotato [Ipomoea batatas (L.) Lam. $(2 n=6 x=90)$ ] has been successfully demonstrated to provide provitamin A biofortification in sub-Saharan Africa (SSA) due to its ability to accumulate high levels of $\beta$-carotene, especially in the orange-fleshed types (Mwanga et al. 2011; Low et al. 2009, 2017). However, the crop had been historically grown in SSA as a food security crop with consumers preferring predominantly high dry matter types which are white-fleshed or yellow-fleshed and less nutritious (Low et al. 2017). As a major constituent of dry matter, starch accounts for about $75 \%$ of human caloric intake (Naeem et al. 1997), and consequently, these adapted varieties have been naturally selected 
to have relatively high starch content. Additionally, such adapted varieties have specific textural characteristics after boiling that are preferred by local consumers. Texture and sweetness determine the eating quality of sweetpotato, both of which depend on the quality and quantity of carbohydrates such as cellulose, hemicellulose, pectin, starch, and sugars (Reeve 1967). Starch is the most important carbohydrate in sweetpotato storage root and its composition, size, and shape of granules contributes to eating quality (Reeve 1967; Kitahara et al. 2017).

$\beta$-carotene (BC) is the predominant carotenoid that accumulates in orange-fleshed sweetpotato storage roots and is a precursor of vitamin A. However, the understanding of the genetic basis of accumulation of carotenoids in underground storage roots is still fragmentary in many crops including sweetpotato (Carvalho et al. 2016). Carotenoid biosynthesis occurs in plastids of various forms. In seeds, roots, and tubers, carotenoid biosynthesis occurs in amyloplasts which are starch-storing plastids important for energy storage and gravitropism (Jarvis and Lopez-Juez 2013; Sun et al. 2018). Naturally, amyloplasts store carotenoids in small quantities typically in the form of lutein, zeaxanthin, and violaxanthin (Wurtzel et al. 2012). However, among roots and tubers, sweetpotato stands out for its capacity to induce modification of amyloplasts into crystalline-type carotenoid sequestration substructures called amylochromoplasts, which not only alter the carotenoid storage capacity, but also biosynthesis, causing higher accumulation of $\beta$-carotene in sweetpotato (Zhang et al. 2014). Unlike most staple crops where strategies are needed to manipulate carotenoid biosynthesis and degradation and/or plastid sink strength (Sun et al. 2018) to improve nutritional quality, these processes naturally occur in sweetpotato and can be readily selected in breeding populations.

The modification of amyloplasts, which are the energy stores within the plant cell to store carotenoids, results in starch biosynthesis and carotenoid biosynthesis competing for carbon that leads to the negative association reported in several crops including citrus (Cao et al. 2015), potato (Mortimer et al. 2016), and sweetpotato (Yada et al. 2017). Application of quantitative and population genetic principles, combined with improved experimental and statistical designs, has led to the release of many improved sweetpotato varieties, including orange-fleshed ones, in several countries within SSA recently (Gruneberg et al. 2015; Andrade et al. 2016). However, the actual adoption of many improved orange-fleshed varieties has been limited in part by the negative $\operatorname{starch} / \beta$-carotene correlation and the yet undefined textural characteristics. Therefore, understanding the genetic architecture surrounding the negative association between starch and $\beta$-carotene and the possibility of breaking this linkage is an important objective of breeding programs targeting sweetpotato for food and nutritional security. Although most genes involved in carotenoid and starch/carbohydrate metabolic pathways are well characterized (Yuan et al. 2015) even in sweetpotato (Kang et al. 2017), insights into regulation of the pathways are still generally lacking. Additionally, these metabolic pathways have been studied independent of each other and no study has considered the molecular mechanisms driving the association between starch and carotenoids.

Hexaploid sweetpotato has two closely related subgenomes $\left(\mathrm{B}_{1} \mathrm{~B}_{1} \mathrm{~B}_{2} \mathrm{~B}_{2} \mathrm{~B}_{2} \mathrm{~B}_{2}\right.$; Shiotani and Kawase 1989; Kriegner et al. 2003; Yang et al. 2017). Genetic analyses of sweetpotato are complicated by factors associated with polyploidy and heterozygosity. Such factors include the presence of multiple alleles at marker loci and differential allele dosage across homeologous chromosomes, the possibility of both bivalent and multivalent formation during meiosis, and the possibility of preferential pairing during meiosis (Dufresne et al. 2014). Compared to other crops, genomic tools that could be applied to expedite the breeding process in sweetpotato have been generally lacking due to the complexity of the genome and the relatively small critical mass of scientists working in this crop. However, due to the significant contribution of sweetpotato to humanity, more resources in the recent past have been deployed to develop genomic tools that address this complexity. In the current study, we demonstrate the robustness of reference genomes from two diploid relatives of sweetpotato, Ipomoea trifida and Ipomoea triloba $(\mathrm{Wu}$ et al. 2018), and new bioinformatic tools for polyploids (Wadl et al. 2018; Mollinari et al. 2019; Pereira et al. 2019) in aiding the understanding of genetic architecture of important traits in sweetpotato breeding for SSA. We quantified starch and $\beta$-carotene together with their correlated traits, dry matter (DM) and flesh color (FC), in a segregating population. We report on the quantitative trait loci (QTL) and differentially expressed genes within those loci and explore the negative starch/ $\beta$-carotene association.

\section{Materials and methods}

\section{Field experiments and laboratory analyses of traits}

Data are reported from field experiments carried out in five environments in Peru. The first four environments were grown in Ica, a coastal desert town in the south of Peru, with two treatments (terminal drought and control experiments) for two seasons, while the fifth environment was located at San Ramon in the humid tropics at the beginning of the jungle, under optimal conditions. The terminal 
drought treatment was imposed by stopping irrigation at 70 days after transplanting (DAT) until harvest time at 120 DAT, while the control treatment was irrigated throughout the experiment. The environments were coded as follows: Ica16C, Ica16D, Ica17C, Ica17D, to indicated control and drought treatments at Ica in 2016 and 2017, respectively, while the fifth environment is coded as SR16 to indicate San Ramon in 2016. Details on locations and growing conditions are described in Online Resource 1, as well as in Pereira et al. (2019). We evaluated 315 segregating progeny derived from a cross between Beauregard (B) and Tanzania (T) varieties. Both parents differ in several traits. A representative sample of three storage roots was taken from each field plot and all replications per environment (environment $=a n$ experiment with the complete set of replicated genotypes with varying treatments or seasons or locations). Samples were transported to the nutritional laboratory at the International Potato Center (CIP) for analysis of quality-related traits. The samples were processed by peeling, slicing, and freeze-drying. We measured four correlated traits: DM, starch, BC, and FC_P (flesh color in Peru). DM was measured as a percentage of laboratory dried samples against the fresh weight of $100 \mathrm{~g}$. Starch and BC contents were measured on the freeze-dried samples using near-infrared reflectance spectroscopy (NIRS) according to Tumwegamire et al. (2011). As an indirect measure for $\beta$-carotene, FC_P was scored based on color charts developed in-house for sweetpotato at CIP, on a scale of 1-9 (from white to dark orange). This scale is based on the sweetpotato descriptors jointly developed by CIP, Asian Vegetable Research and Development Center (AVRDC), and the International Board for Plant Genetic Resources (IBPGR) and normally used when flesh color is measured in addition to $\beta$-carotene content (CIP/ AVRDC/IBPGR 1991). To examine the representativeness of the data reported here for our target breeding environments in sub-Saharan Africa, we also analyzed flesh color scores taken from the same population evaluated in six environments of Uganda (FC_U = flesh color in Uganda) in east Africa, i.e., three locations over 2 years (2016 and 2017). The scale used to measure flesh color in Uganda is based on the CIP Color Chart by Burgos et al. (2009) which uses flesh color to estimate levels of $\beta$-carotene on a scale of 1-30 $(1=$ low $\beta$-carotene and $30=$ high $\beta$-carotene $)$, without the actual measurement of $\beta$-carotene. The environments Nam16 and Nam17 were evaluated in Namulonge $\left(0^{\circ} 31^{\prime} 17.99^{\prime \prime} \mathrm{N}\right.$ and $32^{\circ} 36^{\prime} 32.39^{\prime \prime} \mathrm{E}$ ) during 2016 and 2017 , respectively, environments Ser16 and Ser17 were evaluated in Serere $\left(1^{\circ} 29^{\prime} 59.99^{\prime \prime} \mathrm{N}\right.$ and $\left.33^{\circ} 32^{\prime} 59.99^{\prime \prime} \mathrm{E}\right)$ during 2016 and 2017, respectively, whereas environments Kac16 and Kac17 were evaluated in Kachwekano $\left(1^{\circ} 15^{\prime} 0^{\prime \prime} \mathrm{S}\right.$ and $\left.29^{\circ} 57^{\prime} 0^{\prime \prime} \mathrm{E}\right)$ during 2016 and 2017, respectively. Online Resource 2 shows the flesh color of the parents and part of the segregating population.

\section{Data analyses}

\section{Genetic correlation between environments and broad-sense phenotypic heritability}

Variance components were estimated by restricted maximum likelihood (REML) using ASReml-R in a mixed model assuming heterogeneity of variances and genetic correlations across environments. The experiments were analyzed following the $80 \times 4$ alpha lattice design used in field trials. Specifically, the following mixed model was applied:

$y_{i j k l}=\mu+e_{l}+r_{k(l)}+b_{j(k l)}+\left(\boldsymbol{t}_{i}\right)_{l}+\varepsilon_{i j k l}$,

where $y_{i j k l}$ is the phenotype of the $i$ th treatment in the $j$ th block within the $k$ th replicate at the $l$ th environment, $\mu$ is the overall mean, $e_{l}$ is the random effect of the $l$ th environment ( $l=1, \ldots, L ; L=5$ or 6 depending on the trait) with $e_{l} \sim \mathcal{N}\left(0, \sigma_{e}^{2}\right), r_{k(l)}$ is the random effect of the $k$ th replicate ( $k=1, \ldots, K ; K=2$ or 3 depending on the environment) at the $l$ th environment with $r_{k(l)} \sim \mathcal{N}\left(0, \sigma_{r(l)}^{2}\right), b_{j(k l)}$ is the random effect of the $j$ th block $(j=1, \ldots, J ; J=80)$ within the $k$ th replicate at the $l$ th environment with $b_{j(k l)} \sim \mathcal{N}\left(0, \sigma_{b(l)}^{2}\right)$, $\boldsymbol{t}_{\boldsymbol{i}}=\left(t_{i 1}, . ., t_{i l}, . ., t_{i L}\right)^{T}$ is the random effect of the $i$ th treatment $(i=1, \ldots, I ; I=318)$ across the $L$ environments where $\boldsymbol{t}_{\boldsymbol{i}} \sim \mathcal{N}(0, \Sigma)$ with the variance covariance matrix $\sum$ expressing the genetic variances and covariances across the $L$ environments, and $\varepsilon_{i j k l}$ is the random residual error with $\varepsilon_{i j k l} \sim \mathcal{N}\left(0, \sigma_{(l)}^{2}\right)$. The $\sum$ matrix differed depending on the trait. For DM, starch, and FC_P, the variance-covariance matrix $\sum$ was unstructured. For BC, the variance-covariance matrix $\sum$ was obtained by a second-order factor analytic model (FA2), and for FC_U, the $\sum$ was obtained by a first-order factor analytic model (FA1). In addition to the genetic correlations between pairs of environments estimated above, general broad-sense heritabilities $\left(H^{2}\right)$ were approximated as the ratio between genotypic and phenotypic variances, averaged out across the different environments, from the estimated variance components given in the ASReml-R output. The raw data and joint adjusted means from this analysis used in QTL mapping are provided in Online Resource 3.

\section{Quantitative trait loci (QTL) analyses}

The population was genotyped using GBSpoly, a genotypeby-sequencing method optimized for highly heterozygous and polyploid genomes (Wadl et al. 2018). In summary, the concentration of DNA samples was normalized after quality check on $1 \%$ agarose gel and quantification based on the PicoGreen fluorescence-based assay. Next-generation sequencing 64-plex libraries were made based on the GBSpoly protocol (Wadl et al. 2018), while $125 \mathrm{bp}$ 
single-end sequencing was performed on a total of 40 sequencing lanes (8 lanes for each of the 5 libraries) of the Illumina HiSeq 2500 platform. We aligned the GBS tags against the diploid relatives of sweetpotato, I. trifida and I. triloba reference genomes (Wu et al. 2018) using Bowtie2 (Langmead and Salzberg 2012), and obtained the allele read counts per locus using the Tassel-GBS pipeline (Glaubitz et al. 2014) modified for polyploids (Pereira et al. 2018). The read counts were ultimately used for dosage calling in the software SuperMASSA (Serang et al. 2012) with the help of VCF2SM script (Pereira et al. 2018). Single-nucleotide polymorphisms (SNPs) with read depth $<20,>25 \%$ missing data and significant segregation distortion $\left(p<5 \times 10^{-4}\right)$ were filtered out (Mollinari et al. 2019). A genetic linkage map was developed using MAPpoly software for linkage mapping in polyploids (Mollinari and Garcia 2019) based on the dosage calls. The integrated map had 15 linkage groups (LGs) containing 30,684 GBSpoly-generated and phased SNPs with a total length of $2708.4 \mathrm{cM}$ and an average distance between markers of about $0.09 \mathrm{cM}$ (Mollinari et al. 2019). The phasing procedure was based on parental genotypes, and their inheritance patterns were observed in the offspring individuals. More specifically, the phasing algorithm used the LOD scores of pairwise markers analysis as a primary source of information to sequentially position the allelic variants in specific homologs. For situations where pairwise analysis had limited power to detect the linkage phase (LOD score $<10.0$ ), the algorithm used the likelihood of multiple markers in a hidden Markov model. Further details are described in Mollinari et al. (2019). The QTL genotype conditional probabilities based on the map and the adjusted genotypic means above were then used in QTL mapping using the QTLpoly software (https://github.com/guilherme-pereira/ qtlpoly), a QTL mapping approach for polyploids (Pereira et al. 2019).

In brief, we used a random-effect multiple interval mapping (REMIM) model where score-based tests $(\mathrm{Qu}$ et al. 2013) were performed every $1 \mathrm{cM}$ following a stepwise method. First, the forward search added one QTL at a time into a multiple QTL model using a less conservative threshold ( $p$ value $<0.01$ ). Then, the backward elimination tested each QTL again conditional to all the others in the model using a more conservative threshold ( $p$ value $<0.001$ ). Under the more conservative threshold, forward and backward procedures were repeated until no more QTLs were added or dropped from the model. We avoided a region of $15 \mathrm{cM}$ on either side of QTLs already in the model when searching for a new QTL. QTL heritabilities $\left(h_{\mathrm{QTL}}^{2}\right)$ were computed as the ratio of QTL and total variances, which were estimated using restricted maximum likelihood (REML) as implemented in the R package Sommer (Covarrubias-Pazaran 2016).

\section{Gene expression profiling}

Gene expression profiling of root development in Beauregard was reported previously by $\mathrm{Wu}$ et al. (2018) and included replicated (four biological replicates) RNA-sequencing datasets for total roots at 10 days after transplanting (DAT) and 20 DAT, fibrous roots at 30 DAT, 40 DAT, and 50 DAT, and storage roots at 30 DAT, 40 DAT, and 50 DAT. Tanzania plants were grown in parallel with the "Beauregard" plants as previously described (Wu et al. 2018) and harvested at 10, 20, 30, 40, and 50 DAT; four replicates were generated. The roots were classified at 30,40 , and 50 DAT into fibrous and storage roots based on diameter as described by $\mathrm{Wu}$ et al. (2018). Tanzania RNA was isolated, and libraries were constructed and sequenced as described by Wu et al. (2018). To assess expression abundances, both Beauregard and Tanzania RNA-sequencing reads were cleaned, aligned to the $I$. trifida genome, and fragments per kb exon model per million mapped reads (FPKM) were determined as previously described in Lau et al. (2018). For the final FPKM matrix, genes encoded by the chloroplast were removed. Pearson's correlation coefficients and principal component analyses were performed in $\mathrm{R}$ (v3.5.0) using the $\log 2(\mathrm{FPKM}+1)$ values. To identify differentially expressed genes (DEG), uniquely mapping reads overlapping gene models were counted using HTSeq (v0.6.1p1; Anders et al. 2015) with the following options: - stranded $=$ reverse - minaqual $=10$ -type $=$ exon - mode $=$ union; DESeq2 (v1.22.2; Love et al. 2014) was used for detecting differential expression. Differential expression between Beauregard and Tanzania for each timepoint and root type combination was conducted using the contrasts function in DESeq2 to test whether $\log 2$ fold change was equal to 0 for each pair of contrasts. A $\log 2$ foldchange (lfc) threshold of 2, along with an adjusted $p$ value cutoff of 0.01 was used. The DESeq2 function "lfcshrink" was used to help restrain the high $\log 2$ fold changes of genes that had low expression values. Gene ontology (GO) term enrichment tests were performed on sets of DEGs using the "weight01" algorithm and Fisher's exact test implemented in the R package topGO (v2.34.0; Alexa and Rahnenfuhrer 2019) using all genes with GO terms as background. The "p.adjust" function in R was used to implement the FDR method (Benjamini and Hochberg 1995) and correct the $p$ values for multiple testing. The $p$ values were then filtered at a level of 0.05 .

\section{Locating the markers of QTL within the reference genome to infer candidate genes}

We used the markers at the peak of QTL identified for each trait and their support intervals to query the reference genome using V3 of the I. trifida genome assembly (Wu et al. 2018). An initial set of candidate carotenoid 
biosynthetic and metabolism genes were obtained from $\mathrm{Wu}$ et al. (2018) and refined using alignments against UniRef100.

\section{Results}

\section{Phenotypic performance: Impact of environment on traits}

We measured dry matter, starch, $\beta$-carotene, and flesh color of a biparental population segregating for these traits and grown in multiple environments in Peru and Uganda (Online Resource 3). Genetic correlations between each pair of environments were high for the four traits measured (ranging from $r=0.70$ to $r=0.99$ ) including genetic correlations between environments in Peru and Uganda for FC (Online Resource 4). Consequently, broad-sense heritability $\left(H^{2}\right)$ estimates were also high for all traits: $\mathrm{DM}=0.61$, starch $=0.77, \mathrm{BC}=0.91, \mathrm{FC} \_\mathrm{P}=0.92$, and FC_U $=0.89$ (Online Resource 4). Based on the predicted means, DM was highly positively correlated with starch $(r=0.89)$ and negatively correlated with BC $(r=-0.63)$, FC_P $(r=-0.57)$ and FC_U $(r=-0.59)$. BC was negatively correlated with starch $(r=-0.76)$ and positively with FC_P $(r=0.89)$ and FC_U $(r=0.89)$. As expected from the genetic correlation above, FC_P and FC_U were highly and positively correlated $(r=0.84)$, but negatively correlated with starch $(r=-0.71$ for FC_P and $r=-0.70$ for FC_U, respectively; Fig. 1).

\section{Quantitative trait loci (QTL) associated with quality-related traits}

We analyzed QTL for four correlated traits in sweetpotato: DM, starch, BC, and FC (FC_P and FC_U) based on an integrated genetic map of the 15 LGs of sweetpotato spanning 2,708.4 centimorgans (cM). This was made possible with the availability of anchored reference genomes from two diploid relatives of sweetpotato, I. trifida and $I$. triloba (Wu et al. 2018), and new linkage and QTL mapping methods for polyploids (Mollinari et al. 2019; Pereira et al. 2019). Except for DM and FC_U, which had additional minor QTL on LG1, LG3 and LG7 (DM), and LG4 (FC_U), the major QTL explaining the observed variation for the traits in the mapping population were co-localized on LG3 and LG12 (Fig. 2, Online Resource 5). The colocalized QTL on LG3 with peaks for all traits between 36.14 and $37.44 \mathrm{cM}$ explained $37.4 \%, 51.2 \%, 50.2 \%$, $53.6 \%$, and $48.8 \%$ of observed variation in DM, starch, BC, FC_P, and FC_U, respectively (Table 1). The colocalized QTL on LG12 with peaks for all traits between 146.02 and $150.05 \mathrm{cM}$ explained $11.2 \%, 17.0 \%, 29.0 \%$, $29.3 \%$, and $27.7 \%$ of observed variation in DM, starch,

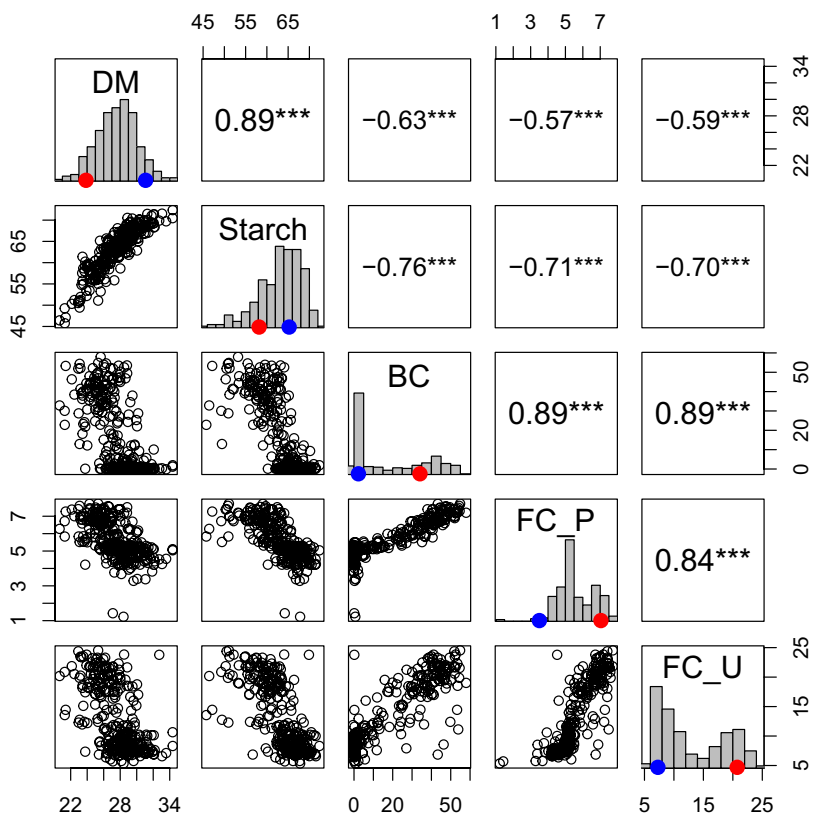

Fig. 1 Correlation coefficients $(* * * p<0.001)$ among genotypic means for dry matter $(\mathrm{DM})$, starch, $\beta$-carotene $(\mathrm{BC})$, flesh color in Peru (FC_P) and Uganda (FC_U). The red and blue dots indicate the mean value of Beauregard and Tanzania, respectively

BC, FC_P, and FC_U, respectively. The additional QTL for DM on LG1, LG3, and LG7 explained 6.9\%, 6.2\%, and $6.0 \%$, respectively, while the additional QTL on LG4 for FC_U explained $3.2 \%$ of the observed variation. The physical positions of the QTL peaks as well as their support intervals are shown in Online Resource 6.

Based on the QTL results, we examined the contribution of parental haplotypes in the major QTL on LG3 and LG12 (Fig. 3). We observed that both parents contributed major alleles with similar allelic effects on the traits at the LG12 QTL, but only Beauregard contributed the major allelic effect with effect on traits at the LG3 QTL (Fig. 3). In fact, additive allele effect estimates from these traits show the same contributing haplotypes in completely opposite directions, i.e., the alleles ( $d$ from QTL on LG3, and $d$ and $l$ from QTL on LG12) that were involved in decreasing the means for DM and starch were the same alleles responsible for increasing the means for $\mathrm{BC}$ and $\mathrm{FC}$ (Fig. 3). These results indicate that haplotypic variations within these two regions are responsible for the observed negative association between starch and BC in sweetpotato. Given that the two parents are contrasting for these traits, these results indicate that even though both contribute haplotypes with similar allelic effects within the QTL on LG12, the interaction between these alleles with those within the QTL on LG3 determines the accumulation or lack of accumulation of $\beta$-carotene in the storage roots. 
Fig. 2 Quantitative trait loci (QTL) profiles as $\mathrm{LOP}=-$ $\log 10(p)$ for dry matter (DM), starch, $\beta$-carotene (BC), flesh color in Peru (FC_P) and Uganda (FC_U) along the Beauregard $\times$ Tanzania sweetpotato genetic map. Triangles show the location of QTL peaks

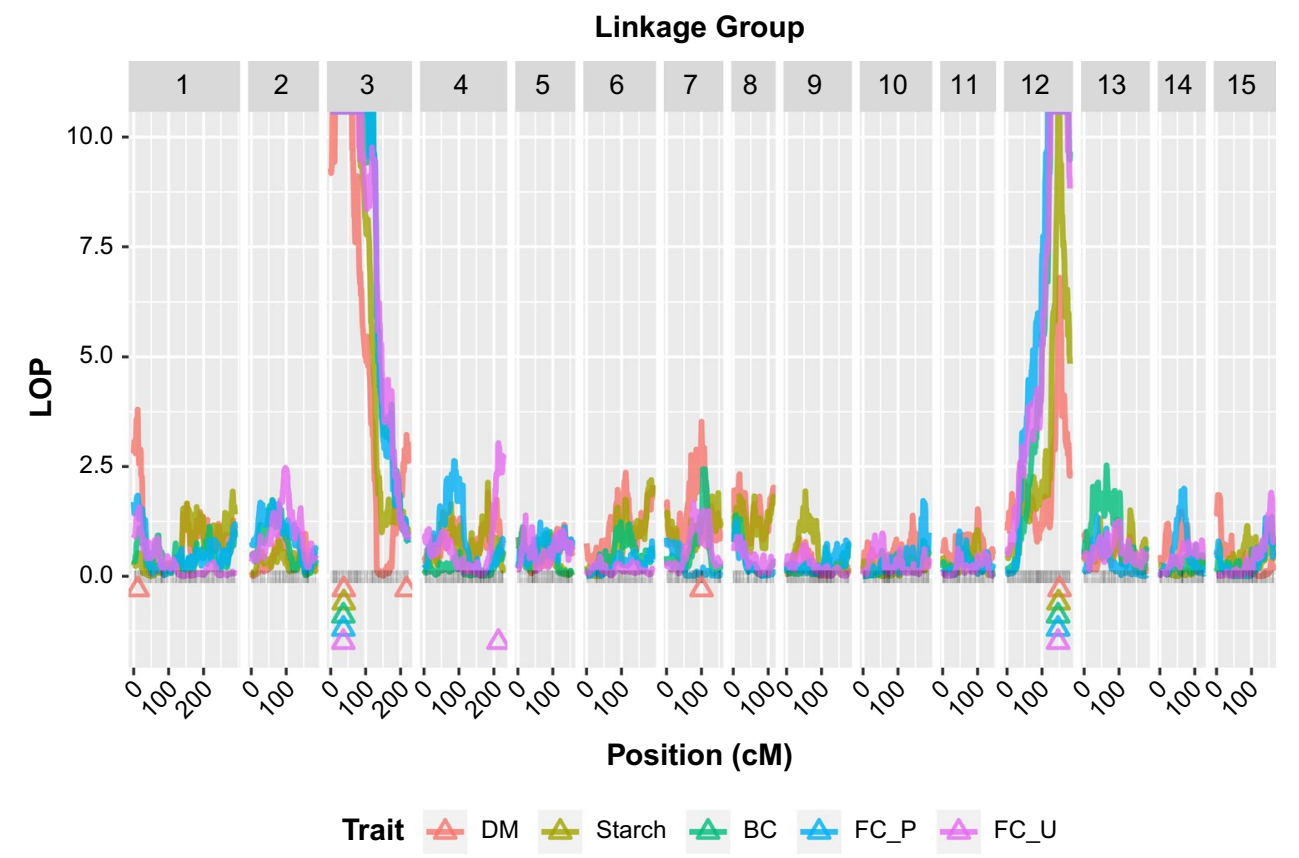

\begin{tabular}{|c|c|c|c|c|c|c|c|c|}
\hline Trait & QTL & $\mathrm{LG}^{\mathrm{a}}$ & $\operatorname{Pos}^{\mathrm{b}}(\mathrm{cM})$ & $\mathrm{SI}^{\mathrm{c}}(\mathrm{cM})$ & Score & $p$ value & $\sigma_{\mathrm{QTL}}^{2}$ & $h_{\mathrm{QTL}}^{2}{ }^{\mathrm{d}}$ \\
\hline \multirow[t]{5}{*}{ DM } & 1 & 1 & 11.41 & $0.00-21.02$ & 158.93 & $1.59 \mathrm{e}-04$ & 0.6590 & 0.069 \\
\hline & 2 & 3 & 37.44 & $4.68-62.06$ & 604.15 & $<1.00 \mathrm{e}-16$ & 3.5713 & 0.374 \\
\hline & 3 & 3 & 217.13 & $193.17-222.06$ & 133.93 & $6.00 \mathrm{e}-04$ & 0.5904 & 0.062 \\
\hline & 4 & 7 & 100.26 & $65.46-113.08$ & 151.34 & $2.99 \mathrm{e}-04$ & 0.5702 & 0.060 \\
\hline & 5 & 12 & 150.05 & $146.02-155.04$ & 264.05 & $1.57 \mathrm{e}-07$ & 1.0657 & 0.112 \\
\hline \multirow[t]{2}{*}{ Starch } & 1 & 3 & 37.44 & $0.00-84.32$ & 849.10 & $<1.00 \mathrm{e}-16$ & 21.3694 & 0.512 \\
\hline & 2 & 12 & 147.31 & $146.02-150.05$ & 435.34 & $<1.00 \mathrm{e}-16$ & 7.0820 & 0.170 \\
\hline \multirow[t]{2}{*}{$\mathrm{BC}$} & 1 & 3 & 36.14 & $0.00-121$ & 1067.07 & $<1.00 \mathrm{e}-16$ & 336.9740 & 0.502 \\
\hline & 2 & 12 & 146.02 & $124.12-176.02$ & 828.83 & $<1.00 \mathrm{e}-16$ & 194.5965 & 0.290 \\
\hline \multirow[t]{2}{*}{ FC_P } & 1 & 3 & 36.14 & $0.00-122.1$ & 1262.29 & $<1.00 \mathrm{e}-16$ & 1.1444 & 0.536 \\
\hline & 2 & 12 & 146.02 & $117.02-180.05$ & 944.49 & $<1.00 \mathrm{e}-16$ & 0.6259 & 0.293 \\
\hline \multirow[t]{3}{*}{ FC_U } & 1 & 3 & 36.14 & $0.00-88.10$ & 1064.73 & $<1.00 \mathrm{e}-16$ & 28.5757 & 0.488 \\
\hline & 2 & 4 & 213.05 & 200.09-227.13 & 135.98 & $9.20 \mathrm{e}-04$ & 1.8504 & 0.032 \\
\hline & 3 & 12 & 146.02 & $121.41-176.02$ & 794.68 & $<1.00 \mathrm{e}-16$ & 16.2076 & 0.277 \\
\hline
\end{tabular}

${ }^{a}$ Linkage group

${ }^{\mathrm{b}}$ Position in centiMorgans

${ }^{c}$ Support interval in centiMorgans

${ }^{\mathrm{d}}$ Proportion of total variance explained by a QTL

\section{Differential gene expression during storage root development}

The co-localization of QTL for the above traits indicated that starch (a major constituent of DM) and carotenoid biosynthesis and accumulation were connected through the interaction of alleles within QTL on LG3 and LG12. To identify candidate genes within our QTL, gene expression profiling datasets from developing roots of Beauregard and Tanzania were examined. Replicated global gene expression profiles were generated from whole Beauregard and Tanzania roots at 10 DAT and 20 DAT as well as fibrous and storage roots at 30, 40, and 50 DAT (Online Resource 7, Online Resource 8). Pearson's correlation analyses of replicates revealed a high degree of reproducibility between biological replicates (Online Resource 9). Principal component analyses (PCA) showed separate clustering of the 30 DAT, 40 DAT, and 50 DAT fibrous roots in Beauregard compared to their corresponding storage roots suggestive of programmed changes in expression 
QTL on LG 3 (36.14-37.44 cM)
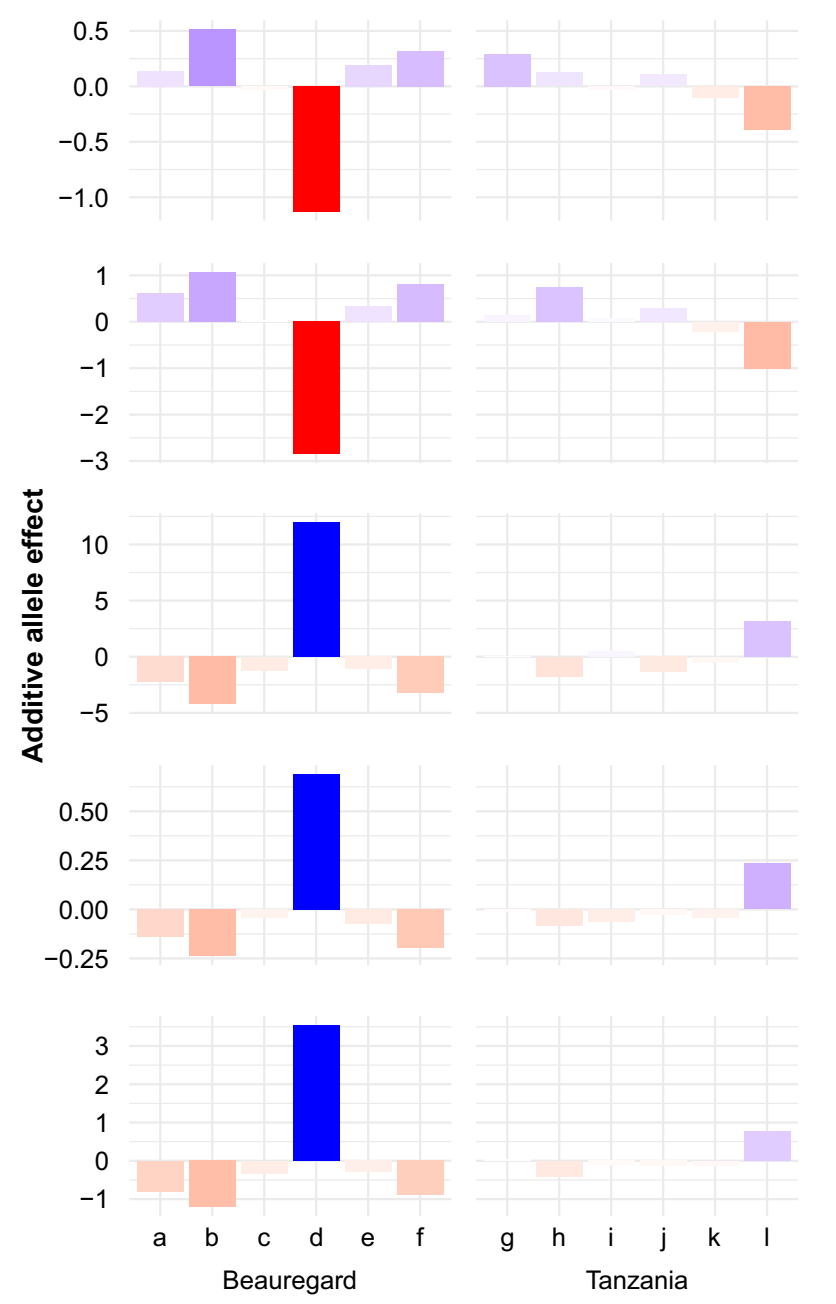

QTL on LG $12(146.02-150.05 \mathrm{cM})$
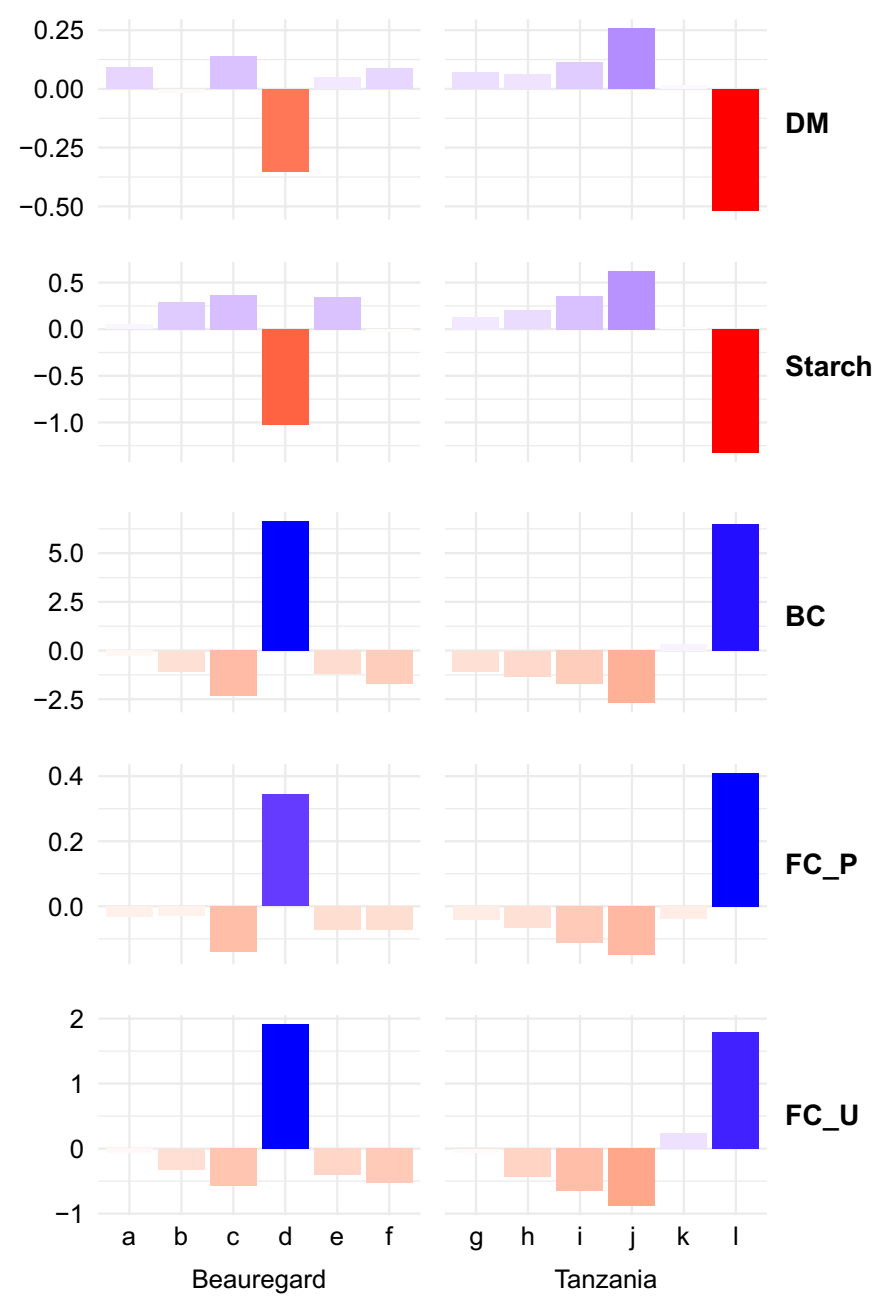

\section{Parental alleles}

Fig. 3 Additive allele effect estimates for co-localized QTL on LG3 and LG12 (map position of the QTL peaks in parenthesis) for dry matter (DM), starch, $\beta$-carotene (BC), and flesh color in Peru (FC_P)

profiles in fibrous versus storage roots (Online Resource 10). However, for Tanzania, only temporal separation of the samples was observed and no differentiation of fibrous roots relative to the storage root samples was observed in the PCA plot. Thus, while Tanzania roots were sampled for fibrous versus storage roots based on root diameter ( $\leq 2.5 \mathrm{~mm}$ and $\geq 2.5 \mathrm{~mm}$, respectively), they were not well differentiated based on gene expression profiles, consistent with their longer maturity period (150 days) relative to Beauregard (90 days). Indeed, determination of differentially expressed genes with DESeq2 of storage roots versus fibrous roots for Beauregard and Tanzania revealed substantially more differentially expressed genes in Beauregard relative to Tanzania at 30,40, and 50 DAT (Online and Uganda (FC_U). Letters $a$ through $f$ and $g$ through $l$ represent the six haplotypes for the specific QTL for Beauregard and Tanzania, respectively

Resource 11) with no differentially expressed genes in Tanzania at 40 DAT storage roots versus fibrous roots. Gene ontology (GO) enrichment analysis of differentially regulated genes in Beauregard at 30 DAT revealed upregulation of genes involved in transcription regulation (Online Resource 12), while at 40 DAT, multiple GO terms involved in cell wall modification were observed in up-regulated genes, and at 50 DAT, GO terms associated with starch biosynthesis, response to sucrose, cell wall organization, and regulation of meristem growth were observed in up-regulated genes. In Tanzania, similar GO term enrichment was observed (Online Resource 12), but the numbers of genes were substantially less than and were not temporally synchronized with Beauregard. 


\section{Candidate genes within QTL of interest}

Starch and carotenoid metabolisms are well characterized in plants, and the major pathways are well documented. The colocated QTL covered a large area that contained many genes (Online Resource 5, Online Resource 7, Online Resource 8 ) as our mapping population (315 progenies) was not large enough to narrow down the QTL region to single, causative genes. Therefore, we focused on the major reported rate-limiting genes of starch and carotenoid metabolism within these regions including genes differentially expressed between Beauregard and Tanzania which differ significantly in their carotenoid content. Wu et al. (2018) reported a significant single-nucleotide polymorphism (SNP) located on LG3 within the phytoene synthase gene (PSY), a rate-limiting gene in the carotenoid biosynthesis and degradation pathway (Sun et al. 2018) associated with flesh color in 16 orange-fleshed and white-fleshed parents of an African breeding population. The peak of the QTL on LG3 shared by BC and FC is at 2,994,719 bp, and the peak shared by DM and starch is at $3,185,578 \mathrm{bp}$. The $P S Y$ gene (itf03g05110) is located between 3,117,946 and $3,122,156 \mathrm{bp}$ and in close proximity to these two peaks (Fig. 4a). Gene expression comparisons between Beauregard

A

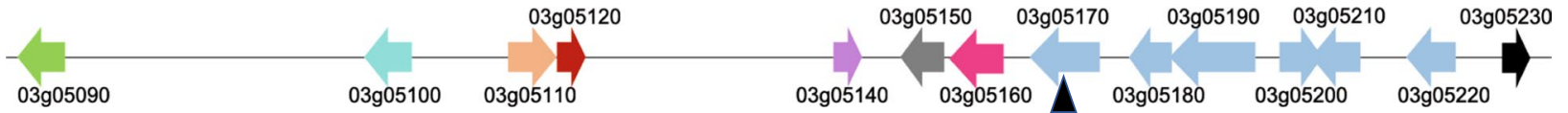

B

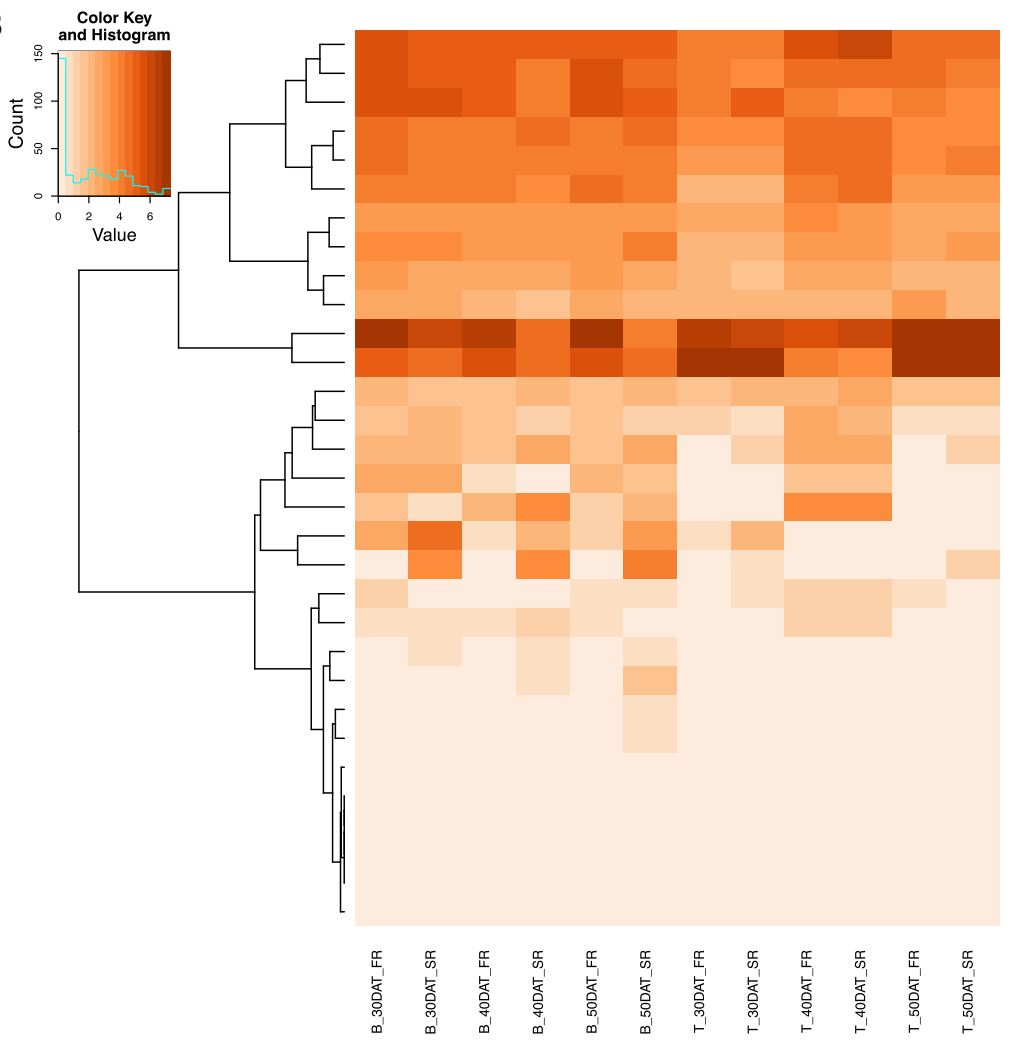

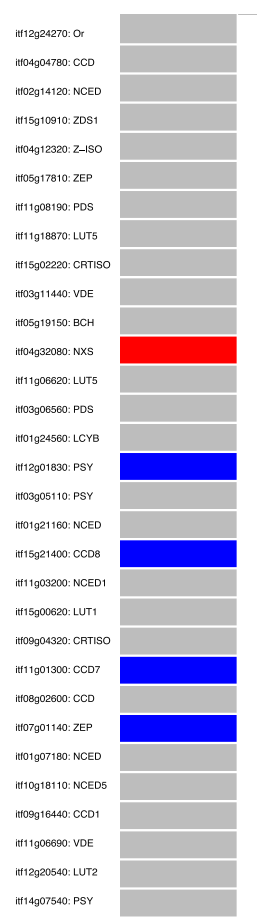

$\mathscr{n}$
市
ò

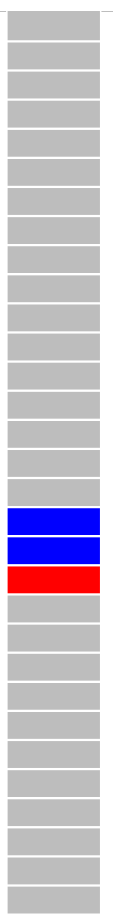

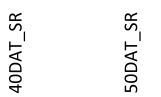

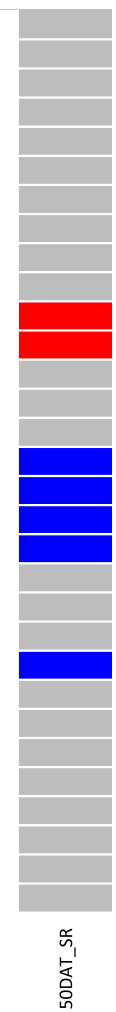

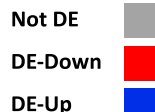

Fig. 4 Characterization of the QTL on LG3 underlying starch and $\beta$-carotene. a Genes are noted by arrows: Homeodomain-like superfamily protein (green); sucrose synthase (aqua), phytoene synthase (lt. orange), glutathione S-transferase (burgundy), AMP-dependent synthetase and ligase family protein (lilac), RAB homolog (gray), polyamine oxidase (magenta), P-loop containing nucleoside triphosphate hydrolase superfamily protein (Lt. blue), and conserved hypothetical (black). Black arrowhead denotes marker S3_3185578. b Left panel: Expression abundances (log2 fragments per kilobase per exon model per million mapped reads (FPKM)) of candidate genes involved in carotenoid metabolism are shown in the heat map below each gene for Beauregard (B) and Tanzania (T) for storage roots (SR) and fibrous roots (RF) at 30, 40, and 50 days after transplant- ing (DAT). Key code value indicates $\log 2$ FPKM and count indicates the number of samples (sample=one gene per sampling) with that FPKM value shown as a histogram. Gene identifiers and gene name abbreviations are listed to the right of the heat map. $\mathrm{BCH}, \beta$-carotene hydrolase; CCD, carotenoid cleavage dioxygenases; CRTISO, carotene isomerase; LUT, lutein deficient; LYCB, lycopene b-cyclase; NCED, 9-cis-epoxycarotenoid dioxygenase; NXS, neoxanthin synthase; OR, ORANGE protein; PDS, phytoene desaturase; PSY, phytoene synthase; VDE, violaxanthin de-epoxidase; ZEP, zeaxanthin epoxidase; ZDS, zeta-carotene desaturase; Z-ISO, z-carotene isomerase. Right panel: Differentially expressed genes based on the comparison of Beauregard versus Tanzania storage roots (color figure online) 
and Tanzania are confounded by the longer maturity of Tanzania relative to Beauregard. However, Beauregard accumulates carotenoids in both fibrous and storage roots starting at 30 DAT (Gemenet, pers. comm.), while Tanzania fails to accumulate significant carotenoids even at maturity (Online Resource 2). Thus, to determine if the BC QTL on LG3 was associated with expression differences of PSY, we examined gene expression profiles in 30, 40, and 50 DAT fibrous and storage roots of Beauregard and Tanzania. PSY was expressed in all sampled Beauregard roots with peak levels present in 40 DAT storage roots (Fig. 4b, Online Resource 13). $P S Y$ was also expressed in Tanzania roots with the highest expression abundances in 10 DAT, 20 DAT, and 40 DAT fibrous and storage roots with no expression in 30 DAT storage roots and extremely low expression observed at 50 DAT fibrous and storage roots. In 50 DAT storage roots, $P S Y$ was differentially expressed between Beauregard and Tanzania $(\log 2 \mathrm{fc}=2.34$, adj. $p$ value $4.2 \mathrm{E}-6$, respectively; Fig. $4 \mathrm{~b}$, Online Resource 13).

Three other genes involved in carotenoid biosynthesis and metabolism underlie carotenoid-related QTL including 15-cis-phytoene desaturase (itf03g06560) and violaxanthin de-epoxidase (itf03g11440) that underlie QTL for $\mathrm{BC}$ and FC and lycopene $\beta$-cyclase (itf04g32080) which underlies FC (Fig. 4b, Online Resource 13). Of specific interest is itf04g32080 as similarly to PSY, it was associated with flesh color in a panel of 16 orange-fleshed and white-fleshed parents of an African breeding population (Wu et al. 2018); itf04g32080 is down-regulated between Beauregard and Tanzania in 30 and 50 DAT storage roots (Fig. 4b, Online Resource 13).

Interestingly, $P S Y$ is within $12.2 \mathrm{~kb}$ of sucrose synthase (SuSY; itf03g05100), with no intervening genes (Fig. 4a). There is increasing evidence that starch biosynthesis in amyloplasts is dependent on ADP-glucose synthesized in the cytosol via $\mathrm{SuSY}$ which is transported to the amyloplasts. SuSY was expressed at similar levels in 10 and 20 DAT roots of both Beauregard and Tanzania (Online Resource 7, Online Resource 8); however, beginning at 30 DAT in Beauregard, fibrous and storage roots differ in $\mathrm{SuSY}$ expression abundance with no expression detected in Beauregard storage roots at 50 DAT. This contrasts with Tanzania in which $S u S Y$ levels remain elevated throughout the time course in both fibrous and storage roots. In 30 DAT storage roots, $S u S Y$ was differentially regulated in Beauregard relative to Tanzania $(\log 2 \mathrm{fc}=-2.59$; adj. $p$ value $=1.8 \mathrm{E}-12$; Online Resource 14).

The peak of the QTL associated with BC on LG12 was located within itf12g24290 (marker S12_22131994; Fig. 5a) which is annotated as SU(VAR)3-9. Nearby $(5.7 \mathrm{~kb})$ is a homolog of the ORANGE (Or) gene (itf12g24270), originally identified in cauliflower, and responsible for acting on and regulating $P S Y$ to allow modification of amyloplasts into chromoplasts ( $\mathrm{Lu}$ et al. 2006). Or2018 is hypothesized to be the molecular switch for chromoplast biogenesis (Sun et al. 2018). A homolog of the $\mathrm{Or}$ gene ( $\mathrm{IbOr}$ ) was cloned from sweetpotato and shown to function in the accumulation of carotenoids in sweetpotato storage roots (Kim et al. 2013). Interestingly, itf $12 g 24270$ but not itf $12 g 24290$ is highly expressed in both Beauregard and Tanzania sweetpotato roots throughout our time course, indicating that $\mathrm{Or}$ is the major gene associated with carotenoid/starch accumulation at this major QTL locus (Fig. 5b); Or was not differentially expressed in any comparison of Beauregard versus Tanzania roots using our $\log 2 \mathrm{fc}$ cutoff of 2 . Another gene of interest within this QTL region is itf12g26180, a Glycogen/starch synthase, ADP-glucose type, which synthesizes starch from the $S u S Y$-catalyzed cytosolic ADP-glucose precursor.

A

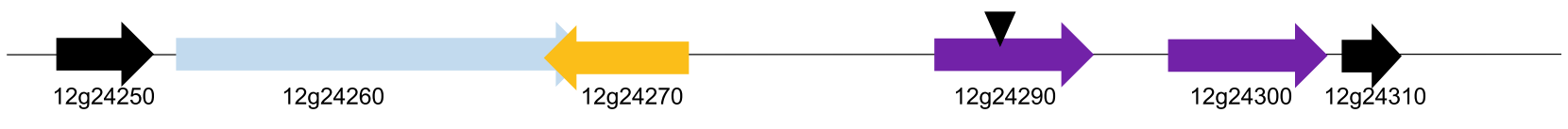

B

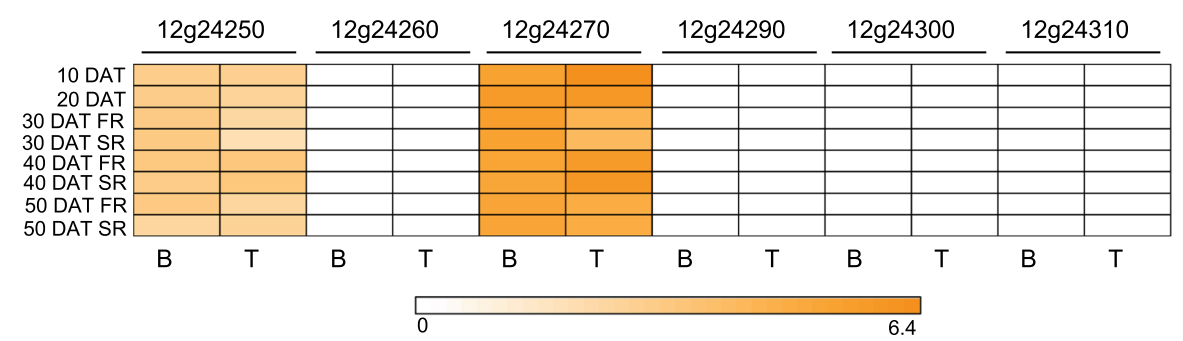

Fig. 5 Region on LG12 underlying $\beta$-carotene levels. a Genes are noted by arrows: conserved hypothetical (black), P-loop containing nucleoside triphosphate hydrolase superfamily protein (lt. blue), Orange (orange), and SU(VAR)3-9 homolog (purple). Black arrowhead denotes marker S12_ 22131994. b Expression abundances $(\log 2$ fragments per kilobase per exon model per million mapped reads) are shown in the heat map below each gene for Beauregard (B) and Tanzania (T). DAT, days after transplanting, $S R$ storage roots, $F R$ fibrous roots (color figure online) 


\section{Discussion}

We have applied novel methods to map and study QTL in hexaploid sweetpotato. Compared to previous mapping efforts in sweetpotato where mapping was based on independent homeologous groups, it is now possible to use SNP dosage markers to recover all the haplotypic information and to build a completely integrated genetic map (Mollinari et al. 2019). We were able to distinguish 12 different haplotypes corresponding to the six possible alleles at a locus by two hexaploid parents with a potential of up to 400 possible allele combinations at a given locus in progeny. Conditional probabilities of the (400) QTL genotypes at each locus were estimated based on the grouped, ordered, and phased map based on hidden Markov models adapted for polyploids. Using this method, multiple QTL mapping is performed, so that the search for new QTL is conditioned to all the other QTL already in the model (Pereira et al. 2019). Although previous studies in sweetpotato have reported QTL for quality-related traits including $\beta$-carotene (flesh color), dry matter, and starch (Cervantes-Flores et al. 2011; Zhao et al. 2013; Xiao-xia et al. 2014; Zhang et al. 2016; Yada et al. 2017), such studies following the pseudo-testcross approach have not contributed substantially towards applied breeding as they present a challenge in comparison with other studies. The current study provides a major improvement in the potential of marker-assisted breeding in sweetpotato.

We present results showing relatively high genetic correlations among pairs of environments and broad-sense heritability across environments, indicating that the studied traits are less affected by the environment and therefore minimal genotype-by-environment interaction is expected. These findings imply that the results presented here are likely to be repeatable across other environments. For most traits, several progenies had mean values higher than the better parent. These can be attributed to segregation and reassortment of alleles due to hybridization or to transgressive inheritance (Goulet et al. 2017). Evidence of transgressive inheritance is provided in the case of $\mathrm{BC}$, for instance, where both parents contribute similar additive allele haplotypes on LG12 that increase BC and reduce starch, yet the parents are contrasting for the two traits. This negative association between $\beta$-carotene and starch content is well established in sweetpotato (Gruneberg et al. 2005; Cervantes-Flores et al. 2011; Yada et al. 2017) and citrus (Cao et al. 2015), among other crops.

The $P S Y$ locus, which is a rate-limiting gene in carotenoid biosynthesis, was previously reported to be associated with flesh color in 16 parents of an east African sweetpotato breeding population in Uganda ( $\mathrm{Wu}$ et al. 2018), through a candidate gene association mapping approach. According to Foss et al. (2007), a phenotype is affected by both cis-acting (local) variation on the actual genes affecting the trait, as well as transacting (distant) variation, e.g., transcription factors, which may be located in a distant region of the genome away from the target gene. We were able to show cis- and trans-acting genes within QTL on LG3 and LG12 explaining the negative association between starch and $\beta$-carotene content in sweetpotato storage roots. The finding that major genes involved in chromoplast biogenesis, starch biosynthesis, and rate-limiting genes for carotenoid biosynthesis were located within the two QTL regions, indicated that activity surrounding chromoplast biogenesis determines the level of carotenoids accumulated and displacement of starch. Our results agree with the findings of Lu et al. (2017) in sweet orange, showing that crystalline chromoplast development explained most of the accumulated carotenoids more than the actual carotenoid metabolic pathways genes. The IbOr gene (Goo et al. 2015) which is located within our QTL on LG12 interacts with PSY gene on LG3 to enhance chromoplast biogenesis and carotenoid accumulation (Lu et al. 2006). The $O r$ gene is known for its posttranscriptional regulation of $P S Y$ protein level and enzyme activity (Sun et al. 2018; Ellison et al. 2018). Evidence of post-transcriptional activity of $O r$ on $P S Y$ was shown by Zhou et al. (2015) where overexpression of $O r$ did not have an effect on the expression of PSY in Arabidopsis thaliana, both in roots and leaves, rather mediated $P S Y$ protein levels and carotenoid content, in cases with high $P S Y$ expression. This is supported by our current results that show no differential expression of $\mathrm{IbOr}$ between Tanzania and Beauregard even though they differ in the amounts of carotenoids, suggesting that the identified QTL are not expression-based and that sequence differences in the loci may confer different phenotypes. For example, Tzuri et al. (2015) and Ellison et al. (2018) showed that a single "golden SNP" within the Or gene is responsible for carotenoid accumulation in melon and carrot, respectively. Candidate gene sequence analysis of the $\mathrm{IbOr}$ is still necessary to confirm if this is also the case for sweetpotato. Our results show that, although Tanzania is white-fleshed, it contains a haplotype at the $\mathrm{IbOr}$ locus that contributes additively to increase $\beta$-carotene content in individuals with a favorable $P S Y$ haplotype, such that transgressive segregation for $\beta$-carotene could be explained by a complementary gene action (Goulet et al. 2017) between both parents. The similar additive allelic effects contributed by both parents at the LG12 QTL locus agree with gene expression data for the IbOr gene where similar and high expression was observed for both Beauregard and Tanzania throughout the time course. The current results also suggest that the variation between accumulation of starch 
or $\beta$-carotene is determined by the haplotype variation present at LG3 as regulated by the LG12 locus. Given that at the time of sampling for gene expression profiling Tanzania had not started differentiation into clear storage roots, future analyses of differentially expressed genes using later development stages of storage roots could further confirm the $P S Y$ and $O r$ relationship in orange-fleshed and non-orange-fleshed sweetpotato. Additionally, since both Beauregard and Tanzania express $P S Y$ and $I b O r$, expression of each gene individually does not confer the ability to accumulate carotenoids in storage roots. The activities of $P S Y$ and $O r$ are important for our study because it is a rate-limiting step, but also relates to the biosynthesis of carotenoids in general. However, the level of $\beta$-carotene present in storage roots is a function of both biosynthetic and degradation processes. This is evidenced in our results by the identification of other carotenoid biosynthesis and degradation genes within the QTL. For instance, the noted lycopene $\beta$-cyclase (itf04g32080) converts lycopene into $\beta$-carotene, while violaxanthin de-epoxidase catalyzes the conversion of violaxanthin into antheraxanthin, both of which are downstream products of $\beta$-carotene degradation (Wu et al. 2018).

We hypothesize that the $S u S Y$ locus linked to $P S Y$ is involved in the starch-carotenoid balance in the chromoplasts. There is increasing evidence that ADP-glucose synthesized in the cytosol by SuSY is critical in determining the rate of starch synthesis in amyloplasts and other plastids and that sucrose and starch biosynthesis is directly connected by SuSY (Naeem et al. 1997; Baroja-Fernández et al. 2004; Muñoz et al. 2005). The current results are supported by our differential gene expression results for SuSY. A recent genome-wide association mapping study in cassava looking at both flesh color and dry matter showed the close association between $P S Y$ with flesh color and $S u S Y$ with DM, allowing them to hypothesize that the association between the two traits may be through physical linkage rather than pleiotropy (Rabbi et al. 2017). This would suggest that haplotype variation within $P S Y$ enhances regulation by the IbOr gene to allow chromoplast biogenesis and carotenoid accumulation and this process inhibits starch synthesis by inhibiting $S u S Y$ activity due to the close linkage between SuSy and PSY. Starch is composed of amylose and amylopectin, and several genes are known to be responsible for its biosynthesis, with the metabolic pathways for starch biosynthesis being different between source and sink (Ohdan et al. 2005). For starch biosynthesis in sink tissue, the main substrate is sucrose, which can be metabolized by $\mathrm{SuSY}$ to either uridine diphosphate glucose (UDP-glucose) or ADP-glucose (Stein and Ganot 2019). Dejardin et al. (1997) showed that SuSY was more important in explaining the rate of starch synthesis when compared to both ADP-Glucose pyrophosphorylase and starch synthase in pea embryos. Additionally, enhanced activity of SuSY increased starch content and ADP-glucose levels in maize endosperms ( $\mathrm{Li}$ et al. 2013). Cytosolic ADPglucose-supported starch synthesis was previously reported in amyloplasts of potato (Naeem et al. 1997) and wheat endosperm (Tetlow et al. 1994) with suggested species-specific differences on the relative importance of this pathway compared to that of glucose-1-phosphate + ATP, depending on the adenylate translocator present.

All of these studies demonstrate $S u S Y$ to be a major determinant of starch content in plant heterotrophic (non-photosynthetic) tissues. They therefore support our hypothesis that starch synthesis in sweetpotato storage roots is dependent on the ADP-glucose synthesized in the cytosol by $\mathrm{SuSY}$ and transported to the amyloplasts and that $S u S Y$ activity is inhibited during chromoplast biogenesis resulting in carotenoid synthesis and accumulation. Additionally, our results show a bimodal distribution for $\mathrm{BC}$ and a normal distribution for DM and starch. It is known that more than two genes affect starch biosynthesis, which is also a major constituent of DM (Ohdan et al. 2005). This is confirmed by our results where additional, minor effect QTL were found for DM. Furthermore, the QTL on LG3 and LG12 together explain a lesser observed variation for DM and starch when compared with the observed variation explained by the same QTL for $\mathrm{BC}$ and FC. This means therefore that there must be more small effect QTL that may be undetected. In addition, broadsense heritabilities were also lower for DM and starch when compared to BC, FC_P, and FC_U, further corroborating the quantitative nature of DM and starch. Despite this, the fact that QTL at LG3 and LG12 jointly explain $48.6 \%$ and $68.2 \%$ of the total observed variation for DM and starch, respectively, supports our hypothesis that these two regions are the most important for both starch and carotenoid biosyntheses and inform the dynamics that surround their accumulation or displacement of each other.

Most studies examining starch and carotenoid biosynthesis and accumulation have been performed with single traits. To the best of our knowledge, this is the first study where a physical linkage between SuSy and PSY has been shown in addition to their association with the chromoplast biogenesis gene Or. Studies on the active mechanisms and regulation among the three candidate genes to further explain the negative association between starch and $\beta$-carotene are necessary. Future fine mapping within the current QTL regions offers an opportunity to study these putative candidate genes better. Toward their application in plant breeding, the analysis of haplotype variation within well-characterized candidate genes will enhance mining of desirable allelic haplotypes from natural populations or target breeding populations which can be selected using functional markers. For those pathways that are not very well defined yet, candidate genes will need to be characterized by the use of reverse genetics using transformation, RNA interference (RNAi), and mutant 
characterization. These will then inform breeding programs on the possibility of breaking genetic linkage among loci through recombination and selection of desirable haplotypes or to apply new crop improvement methods such as gene editing.

\section{Conclusion}

Using novel methods, we are able to explore the genetic architecture surrounding the negative association between starch and $\beta$-carotene content in sweetpotato. Based on data presented here and reports in the literature, we suggest that IbOr gene on LG12 and PSY on LG3 act pleiotropically to modify amyloplasts into chromoplasts for synthesis and accumulation of $\beta$-carotene in orange-fleshed sweetpotato, and that this interaction is more important than the individual expression of each gene individually. We also suggest that this amyloplast modification affects starch content through the direct linkage between $P S Y$ and $S u S Y$ by inhibiting the activity of $S u S Y$ in storage roots of orange-fleshed sweetpotato, thereby reducing the ADP-glucose precursor available from the cytosol for starch synthesis in the amyloplasts. These results will be helpful in designing methods toward genomic-assisted breeding approaches in sweetpotato breeding programs, especially through haplotype variation analysis within the reported candidate genes. We also note that further research is still necessary to better understand the mechanisms and regulations underlying the negative association between starch and carotenoid content.

\section{Author contribution statement}

AK, WJG, GCY, ZBZ, CRB, ZF, and LJMC designed and managed different aspects of the work; DCG, EC, ROM, AK, and WJG designed the experiments at CIP; DCG, FD, VM, AK, RTS, JS, ROM, and WJG carried out field experiments in Peru and Uganda; BAO, DCG, MNK, MD, MG, and GCY prepared the DNA/RNA samples and genotyped the mapping population; GB, TZF, DCG, and VM carried out the laboratory analysis of the traits; GDSP, MM, and ZBZ developed the genetic and QTL mapping software; ZF, CRB, JPH, and LJMC sequenced, annotated, and anchored the reference genome; ZF and CRB sequenced the RNA for gene expression profiling; DCG, GDSP, BDB, JCW, CRB, VM, and MM carried out the data analysis; DCG wrote the manuscript; and all authors read and approved the manuscript.

Acknowledgements The research was supported by a Bill \& Melinda Gates Foundation grant (Grant Number OPP1052983). We wish to acknowledge the technical team in sweetpotato breeding at the International Potato Center (CIP) for running experiments and collecting data. Research at CIP was undertaken as part of the consultative group on international agricultural research (CGIAR)—-Research Program on Roots, Tubers and Bananas (RTB), which is supported by CGIAR Fund Donors (http://www.cgiar.org/about-us/our-funders/). We are grateful to Dr. Jim Lorenzen of BMGF and Dr. Hugo Campos of CIP for providing initial review of the manuscript.

Data Availability The raw data and joint adjusted means used in QTL analyses in the current study are provided as supplementary with this manuscript (Online Resource 3). The RNA-sequencing reads are available in the NCBI Sequence Read Archive under BioProject PRJNA491292 and PRJNA549660. The phased SNPs and genetic map are available interactively at (https://gt4sp-genetic-map.shinyapps.io/ bt_map/).

\section{Compliance with ethical standards}

Conflict of interest On behalf of all authors, the corresponding author states that there is no conflict of interest.

Open Access This article is distributed under the terms of the Creative Commons Attribution 4.0 International License (http://creativeco mmons.org/licenses/by/4.0/), which permits unrestricted use, distribution, and reproduction in any medium, provided you give appropriate credit to the original author(s) and the source, provide a link to the Creative Commons license, and indicate if changes were made.

\section{References}

Alexa A, Rahnenfuhrer J (2019) topGO: enrichment analysis for gene ontology. R package version 2.36.0. https://doi.org/10.18129/ B9.bioc.topGO

Anders S, Pyl PT, Huber W (2015) HTSeq—a Python framework to work with high-throughput sequencing data. Bioinformatics 31:166-169

Andrade MI et al (2016) Alisha', 'Anamaria', 'Bie', 'Bita', 'Caelan', 'Ivone', 'Lawrence', 'Margarete', 'Victoria', Sweetpotato. Hort Sci 51:597-600

Baroja-Fernández E, Muñoz FJ, Zandueta-Criado A, Morán-Zorzano MT, Viale AM, Alonso-Casajús N, Javier Pozueta-Romero J (2004) Most of ADP-glucose linked to starch biosynthesis occurs outside the chloroplast in source leaves. PNAS 101(35):13080-13085

Benjamini Y, Hochberg Y (1995) Controlling the false discovery rate: a practical and powerful approach to multiple testing. J R Stat Soc Ser B Methodol 57:289-300

Burgos G, Caprio R, Sanchez C, Sosa P, Porras E, Espinoza J, Grüneberg W (2009) Guide for using the RHS color chart for selecting for high $\beta$-Carotene sweet potato. Poster at ISTRC, Lima

$\mathrm{Cao} \mathrm{H}$ et al (2015) Carotenoid accumulation affects redox status, starch metabolism, and flavonoid/anthocyanin accumulation in citrus. BMC Plant Biol 15:27. https://doi.org/10.1186/s1287 0-015-0426-4

Carvalho LJCB et al (2016) Natural variation in expression of genes associated with carotenoid biosynthesis and accumulation in cassava (Manihot esculenta Crantz) storage roots. BMC Plant Biol 16:133

Cervantes-Flores JC et al (2011) Identification of quantitative trait loci for dry-matter, starch, and $\beta$-carotene content in sweetpotato. Mol Breed 28:201-216

CIP/AVRDC/IBPGR (1991) Descriptors for sweetpotato. In: Huaman $\mathrm{Z}$ (ed) International board for plant genetic resources, Rome 
Covarrubias-Pazaran G (2016) Genome-assisted prediction of quantitative traits using the $\mathrm{R}$ package sommer. PLoS ONE 11(6): 0156744

Dejardin A, Rochat C, Wuilleme S, Boutin J-P (1997) Contribution of sucrose synthase, ADP-glucose pyro-phosphorylase and starch synthase to starch synthesis in developing pea seeds. Plant Cell Environ 20:1421-1430

Dufresne F, Stift M, Vergilino R, Mable BK (2014) Recent progress and challenges in population genetics of polyploid organisms: an overview of current state-of-the-art molecular and statistical tools. Mol Ecol 23(1):40-69

Ellison SL et al (2018) Carotenoid presence is associated with the Or gene in domesticated carrot. Genetics 210:1497-1508

Foss EJ et al (2007) Genetic basis of proteome variation in yeast. Nat Genet 39:1369-1375

Glaubitz JC et al (2014) TASSEL-GBS: a high capacity genotyping by sequencing analysis pipeline. PLoS ONE 9(2):e90346

Goo YM et al (2015) Overexpression of the sweetpotato $\mathrm{IbOr}$ gene results in the increased accumulation of carotenoid and confers tolerance to environmental stresses in transgenic potato. C R Biol 338: $12-20$

Goulet BE, Roda F, Hopkins R (2017) Hybridization in plants, old ideas, new techniques. Plant Physiol 173:65-78

Gruneberg WJ, Manrique K, Zhang D, Hermann M (2005) G x E interaction for a diverse set of sweetpotato genotypes evaluated across varying ecogeographic conditions in Peru. Crop Sci 45:2160-2171

Grüneberg WJ et al (2012) Advances in sweetpotato breeding from 1992 to 2012. In: Low JW, Nyongesa M, Quinn S, Parker M (eds) Potato and Sweetpotato in Africa: transforming the value chains for food and nutrition security. CABI, Wallingford, pp 3-68

Jarvis P, Lopez-Juez E (2013) Biogenesis and homeostasis of chloroplasts and other plastids. Nat Rev Mol Cell Biol 14:787-802

Kang L et al (2017) Suppression of the b-carotene hydroxylase gene increases b-carotene content and tolerance to abiotic stress in transgenic sweetpotato plants. Plant Physiol Biochem 117:24-33

Kim SH et al (2013) Cloning and characterization of an Orange gene that increases carotenoid accumulation and salt stress tolerance in transgenic sweetpotato cultures. Plant Physiol Biochem 70:445-454

Kitahara et al (2017) Carbohydrate components in sweetpotato storage roots: their diversities and genetic improvement. Breed Sci 67:62-72

Kriegner A, Cervantes JC, Burg K, Mwanga ROM, Zhang DA (2003) A genetic linkage map of sweetpotato (Ipomoea batatas (L.) Lam.) based on AFLP markers. Mol Breed 11:169-185

Langmead B, Salzberg SL (2012) Fast gapped-read alignment with Bowtie 2. Nat Methods 9(4):357

Lau et al (2018) Transcriptomic analysis of sweet potato under dehydration stress identifies candidate genes for drought tolerance. Plant Direct. https://doi.org/10.1002/pld3.92

Li J et al (2013) Enhancing sucrose synthase activity results in increased levels of starch and ADP-glucose in maize (Zea mays L.) seed endosperms. Plant Cell Physiol 54(2):282-294

Love MI, Huber W, Anders S (2014) Moderated estimation of fold change and dispersion for RNA-seq data with DESeq2. Genome Biol 15:550

Low JW et al (2009) Sweetpotato in Sub-Saharan Africa. In: Loebenstein G, Thottappilly G (eds) The Sweetpotato. Springer, Dordrecht, pp 359-390

Low JW, Mwanga ROM, Andrade M, Carey E, Ball A (2017) Tackling vitamin A deficiency with biofortified sweetpotato in sub-Saharan Africa. Glob Food Secur 14:23-30

Lu S et al (2006) The cauliflower $O r$ gene encodes a DnaJ cysteine-rich domain-containing protein that mediates high levels of $\beta$-carotene accumulation. Plant Cell 18:3594-3605
Lu PJ et al (2017) Cytological and molecular characterization of carotenoid accumulation in normal and high-lycopene mutant oranges. Sci Rep 7:761

Mollinari M, Garcia AAF (2019) Linkage analysis and haplotype phasing in experimental autopolyploid populations with high ploidy level using hidden Markov models. BioRxiv https://www.biorx iv.org/content/10.1101/415232v2

Mollinari M, Olokulu B, Pereira GDS, Khan A, Gemenet DC, Yencho C, Zeng Z-B (2019) Unraveling the hexaploid sweetpotato inheritance using ultra-dense multilocus mapping. BioRxiv Preprint. https://doi.org/10.1101/689638

Mortimer CL et al (2016) Product stability and sequestration mechanisms in solanum tuberosum engineered to biosynthesize high value ketocarotenoids. Plant Biotechnol J 14:140-152

Muñoz FJ, Baroja-Fernández E, Morán-Zorzano MT, Viale AM, Etxeberria E, Alonso-Casajús N, Pozueta-Romero J (2005) Sucrose synthase controls both intracellular ADP glucose levels and transitory starch biosynthesis in source leaves. Plant Cell Physiol 46(8):1366-1376

Mwanga ROM, Ghislain M, Kreuze J, Ssemakula GN, Yencho GC (2011) Exploiting the use of biotechnology in sweetpotato for improved nutrition and food security: progress and future outlook. In: Nampala P, Makara MA (eds) Proceedings of the international conference on agro-biotechnology, biosafety and seed systems in developing countries. Science Foundation for Livelihoods and Development, Kampala, Uganda, pp 25-31

Naeem M, Tetlow IJ, Emes MJ (1997) Starch synthesis in amyloplasts purified from developing potato tubers. Plant $\mathrm{J}$ 11(5):1095-1103

Ohdan T, Francisco PB Jr, Sawada T, Hirose T, Terao T, Satoh H, Nakamura Y (2005) Expression profiling of genes involved in starch synthesis in sink and source organs of rice. J Exp Bot 56(422):3229-3344

Pereira GS, Garcia AAF, Margarido GRA (2018) A fully automated pipeline for quantitative genotype calling from next generation sequencing data in autopolyploids. BMC Bioinform 19(1):398

Pereira GDS, Gemenet DC, Mollinari M, Olukolu BA, Diaz F, Mosquera V, Gruneberg WJ, Khan A, Yencho GC, Zeng Z-B (2019) Multiple QTL mapping in autopolyploids: a random-effect model approach with application in a hexaploid sweetpotato full-sib population. BioRxiv Preprint https://doi.org/10.1101/622951

Qu L, Guennel T, Marshall SL (2013) Linear score tests for variance components in linear mixed models and applications to genetic association studies. Biometrics 69(4):883-892

Rabbi IY et al (2017) Genome-wide association mapping of correlated traits in cassava: dry matter and total carotenoid content. Plant Genome. https://doi.org/10.3835/plantgenome2016.09.0094

Reeve RM (1967) A review of cellular structure, starch and texture qualities of processed potatoes. Econ Bot 21(4):294-308

Serang O, Mollinari M, Garcia AAF (2012) Efficient exact maximum a posteriori computation for bayesian SNP genotyping in polyploids. PLoS ONE 7(2):e30906

Shiotani I, Kawase T (1989) Genomic structure of the sweet- potato and hexaploids in Ipomoea trifida (HBK) DON. Jpn J Breed 39:57-66

Stein O, Ganot D (2019) An overview of sucrose synthases in plants. Front Plant Sci 10:95

Sun T, Yuan H, Cao H, Yazdani M, Tadmor Y, Li L (2018) Carotenoid metabolism in plants: the role of plastids. Mol Plant 11:58-74

Tetlow IJ, Blissett KJ, Emes MJ (1994) Starch synthesis and carbohydrate oxidation in amyloplasts from developing wheat endosperm. Planta 194:454-460

Tumwegamire $S$ et al (2011) Evaluation of dry-matter, protein, starch, sucrose, beta-carotene, iron, zinc, calcium and magnesium in east African sweetpotato. Hort Sci 46(3):348-357 
Tzuri G et al (2015) A 'golden' SNP in CmOr governs the fruit flesh color of melon (Cucumis melo). Plant J 82:267-279

Wadl PA et al (2018) Genetic diversity and population structure of the USDA sweetpotato (Ipomoea batatas) germplasm collections using GBSpoly. Front Plant Sci 9:1-13

Wu S et al (2018) Genome sequences of two diploid wild relatives of cultivated sweetpotato reveal targets for genetic improvement. Nat Commun 9:4580

Wurtzel E, Cuttriss A, Vallabhaneni R (2012) Maize provitamin A carotenoids, current resources, and future metabolic engineering challenges. Front Plant Sci 3:29

Xiao-xia Y et al (2014) Identification of QTLs for starch content in sweetpotato (Ipomoea batatas (L.) Lam.). J Integrative Agric 13(2):310-315

Yada B et al (2017) Genetic analysis and association of simple sequence repeat markers with storage root yield, dry matter starch and betacarotene content in sweetpotato. Breed Sci 67(2):140-150

Yang J et al (2017) Haplotype-resolved sweet potato genome traces back its hexaploidization history. Nat Plants 3:696-703

Yuan H, Zhang J, Nageswaran D, Li L (2015) Carotenoid metabolism and regulation in horticultural crops. Hortic Res 2:15036
Zhang MK, Zhang MP, Mazourek M, Tadmor Y, Li L (2014) Regulatory control of carotenoid accumulation in winter squash during storage. Planta 240:1063-1074

Zhang K et al (2016) Development an identification of SSR markers associated with starch properties and $\beta$-Carotene content in the storage root of sweet potato (Ipomoea batatas L.). Front Plant Sci 7:223

Zhao N et al (2013) A genetic linkage map based on AFLP and SSR markers and mapping of QTL for dry-matter content in sweetpotato. Mol Breed 32:807-820

Zhou X, Welsch R, Yang Y, Álvarez D, Riediger M, Yuan H, Fish T, Liu J, Thannhauser TW, Li L (2015) Arabidopsis OR proteins are the major posttranscriptional regulators of phytoene synthase in controlling carotenoid biosynthesis. PNAS 112(11):3558-3563

Publisher's Note Springer Nature remains neutral with regard to jurisdictional claims in published maps and institutional affiliations.

\section{Affiliations}

Dorcus C. Gemenet ${ }^{1}$ (1) $\cdot$ Guilherme da Silva Pereira ${ }^{2} \cdot$ Bert De Boeck $^{3} \cdot$ Joshua C. Wood $^{4} \cdot$ Marcelo Mollinari $^{2}$. Bode A. Olukolu ${ }^{2,11}$ - Federico Diaz ${ }^{3}$. Veronica Mosquera ${ }^{3}$ - Reuben T. Ssali ${ }^{5} \cdot$ Maria David $^{3} \cdot$ Mercy N. Kitavi $^{1}$. Gabriela Burgos $^{3}$ - Thomas Zum Felde ${ }^{3} \cdot$ Marc Ghislain $^{1} \cdot$ Edward Carey $^{6}$. Jolien Swanckaert ${ }^{6} \cdot$ Lachlan J. M. Coin $^{7}$. Zhangjun Fei $^{8}$. John P. Hamilton ${ }^{4} \cdot$ Benard Yada $^{9} \cdot$ G. Craig Yencho ${ }^{2} \cdot$ Zhao-Bang Zeng ${ }^{2} \cdot$ Robert O. M. Mwanga ${ }^{5}$. Awais Khan ${ }^{3,10}$. Wolfgang J. Gruneberg ${ }^{3}$. C. Robin Buell ${ }^{4}$

1 International Potato Center, ILRI Campus, Old Naivasha Road, P.O. Box 25171-00603, Nairobi, Kenya

2 North Carolina State University, Raleigh, NC 27695, USA

3 International Potato Center, Av. La Molina 1895, Lima, Peru

4 Michigan State University, East Lansing, MI 48824, USA

5 International Potato Center, Kampala, Uganda

6 International Potato Center, Kumasi, Ghana

7 University of Queensland, St. Lucia, Brisbane, QLD 4072, Australia
Boyce Thompson Institute, Cornell University, Ithaca, NY 14853, USA

9 National Crops Resources Research Institute (NaCCRI), Namulonge, P.O. Box 7084, Kampala, Uganda

10 Plant Pathology and Plant-Microbe Biology Section, Cornell University, Geneva, NY 14456, USA

11 University of Tennessee, Knoxville, TN 37996, USA 